\title{
Effect of Swim Up Techniques on Sperm Motility and DNA Integrity Versus Unprepared Semen
}

\author{
Shatha S. AL-Marayaty* \\ Ghassan T. Saeed** \\ Hazim I. AL-Ahmed***
}

\author{
HD, ART \\ PhD \\ PhD
}

\begin{abstract}
:
Background: The need for assisted reproduction technologies (ART) for the establishment of pregnancies has steadily increased worldwide. Therefore, it is of vital importance that an efficient sperm preparation technique used for retrieval of high-quality spermatozoa contributes to the creations of high-quality embryos, with high implantation potential.

Objective: to study the effect of swim up technique on human sperm motility and DNA integrity.

Subject and methods: A prospective study carried on 70 samples of human semen; each sample, divided into 2 parts, one part was prepared by swim-up technique and the other not, and then study sperm motility and DNA integrity in both parts. Sperm DNA integrity was determined using a modified alkaline single cell gel electrophoresis (comet) assay and acridine orange test (AOT), and motility was determined by light microscope.

Result(s): the results showed that swim up technique give a significant. increasing in motility percentage and a significant. decreasing in DNA damage $(\mathrm{P}<0.05)$ than unprepared human sperm.

Conclusion(s): Swim up technique for sperm preparation is increasing motility and decreasing DNA damage.
\end{abstract}

Keywords: swim-up technique, DNA integrity, sperm motility.

\section{Introduction:}

Sperm quality and sperm DNA integrity is one of the most important factor in the in vitro fertilization (IVF) laboratory since male infertility accounts for $20-30 \%$ of the infertility cases and treatment options are mainly based on sperm-quality improvement techniques (1), good quality sperm DNA is essential for the accurate transmission of genetic material to the next generation (2), fertilization of an oocyte with an apoptotic spermatozoon has been shown to have detrimental effects on fertilization rate, implantation rate, embryo survival, pregnancy outcome, and miscarriage rates in assisted reproduction treatment, as well as it causes congenital abnormalities in offspring (3). As the need for assisted reproduction technology (ART) procedures for the establishment of pregnancies has steadily increased worldwide, around $7 \%$ of all annual births are thought to be established by ART, which corresponds to 1 million treatments, therefore, it is of vital importance that an efficient sperm preparation technique used for retrieval of highquality spermatozoa contributes to the creations of high-quality embryos, with high implantation potential (4). The main goal with the sperm preparation is to yield highly motile spermatozoa

* Kamal AL-Samuray Hospital

Shatha almarayaty@yahoo.com

** Department of Physiology, Baghdad Collage of

Medicine

*** Biotechnology Research Centre, AL Nahrain University with good morphology and low DNA fragmentation rates, criteria that support the subsequent development of high-quality embryos. (5). Spermatozoa are not only the smallest but also the most polarized cell in the body (sperm head and a flagellum) as it is fulfill their physiological functions, the fertilization of oocyte outside the body in a different individual, the female genital tract (6). The sperm cell's special composition of its plasma membrane with an extraordinary high amount of poly-unsaturated fatty acids, and high membrane fluidity made the male germ cell to be a very specialized and in certain aspects very sensitive cell. The sensitive cell is extremely susceptible to oxidative stress by reactive oxygen species (ROS) (7) and impairing the membrane function, which could be result in loss of fertilizing potential, serious damage of the DNA or even cell death because of the sperm cell's lack of intrinsic reactive oxygen species (ROS)-scavenging systems due to a lack of cytoplasm (which is harboring repair mechanisms in any other cell), in vivo, after normal ejaculation for sexual intercourse, spermatozoa depend on scavenging systems provided by the seminal plasma, which is the biological fluid that contains more antioxidant substances than any other physiological fluid does(8). The most important natural antioxidants in seminal plasma seem to be vitamin C and $\mathrm{E}$, superoxide dismutase , uric acid, glutathione , or the polyamine spermine that acts directly as a free radical scavenger $(9,1011)$. In addition, in vivo, separation of motile sperm most capable of 
fertilizing oocytes from immotile sperm, debris, seminal plasma, and leukocytes is taking place in the female genital tract by active migration through the cervical mucus (12). An ideal sperm processing technique should be gentle and one that recovers a highly functional sperm population.

Material and methods: The prospective study is carried on 70 human semen samples in the laboratories of Biotechnology Research Center, ALNahrain University, and Kamal Al Samuray Hospital in Baghdad, from January 2016 till December 2016. Twenty samples were selected for comet assay test and fifty samples for Acridine orange test before and after preparation.. Their mean age was $32.33 \pm 5.96$ years, not drinker, not smokers, no history of drug intake. The samples were obtained from men after a minimum 3 days of abstinence and ejaculated into a clean, wide-mouthed container. After liquefaction for 30 minutes in $37 \mathrm{C}^{\circ}$ incubator , routine semen analysis was performed manually according to World Health Organization (WHO) to assess semen volume, $\mathrm{pH}$, viscosity, liquefaction, sperm count, sperm motility, sperm agglutination, strict sperm morphology, and cell contamination (WHO 2010). Semen samples with normal parameters (volume 2-6 ml, $\mathrm{pH}$ 7.2-8.0, sperm count $>20 \times 106 / \mathrm{ml}$, sperm motility $>50 \%$, strict sperm morphology $>14 \%$, and insignificant sperm agglutination and cell contamination) were selected for experimental use. The semen were prepared by swim up methods. Add $5 \mathrm{ml}$ Flushing medium to the native semen sample and mix. Centrifuge for 5 minutes at 3500 RPM. Remove supernatant and add $3 \mathrm{ml}$ Flushing medium to the pellet and perform swim-up method.Sperm motility was assessed by light microscope before and after sperm preparation, and DNA integrity was assessed by Comet Assay which is a single cell gel electrophoresis assay (SCGE) for simple evaluation of cellular DNA damage in live cell. Individual cells are mixed with molten agarose before application to the comet slides, these embedded cells are then treated with lysis buffer and alkaline solution, which relaxes and denaturant the DNA. The samples are electrophoresed in a horizontal chamber to separate intact DNA from damaged fragments, samples are dried, Stained with a DNA dyes and visualized by fluorescence microscope. Under fluorescent fields, damage cellular DNA (containing cleavage and strand breaks) will migrate further than intact DNA, producing a classic comet tail shape under the microscope. Extent of DNA damage is usually visually estimated by comet tail measurement The
DNA damage is quantified by measuring the displacement between the genetic material of the nucleus (comet head) and the resulting tail. 50 randomly selected sperm were counted per sample to quantify the comet cell (13), and by Acridine Orange test (AOT) which was reported by Tejada et al (1984) (14). Prepare sperm smear, let it dry, Fixation overnight in menthol-glacial acetic acid (3:1) at room temperature. removed from the fixative and allowed to dry for few minutes before staining, staining with Acridine orange (AO) $(0.19 \mathrm{mg} / \mathrm{mL}$, $\mathrm{pH} 2.5$ ) for 5 minutes at room temperature (staining solution was prepared daily from stock solution consisting of $1 \mathrm{mg}$ AO 1/1000 mL of distilled water and stored in dark at $4{ }^{\circ} \mathrm{C}$. (to prepare the staining solution , $10 \mathrm{~mL}$ of stock solution was added to 40 $\mathrm{mL}$ of $0.1 \mathrm{M}$ citric acid and $2.5 \mathrm{~mL}$ of $0.3 \mathrm{M}$ $\mathrm{Na} 2 \mathrm{HPO} 4,7 \mathrm{H} 2 \mathrm{O}$. All solutions were maintained at room temperature, gently rinse in a stream of distilled water and sealed under a coverslip and viewed by fluorescence microscopy ., Sperm cell heads with good DNA integrity had green fluorescence, and those with diminished DNA integrity had orange - red staining. Sample could scored within 1 hour after staining. Count 50 sperm, and scored the $\%$ of green, yellow -red stain sperm . Statistical analysis: Statistical package for social science version 20 (SPSS 20) was used for both data entry and data analysis. Continuous variable presented as mean $\pm \mathrm{SD}$. Independent sample $t$ test was used to test the significance of association of variables. P-value of $<0.05$ was considered significant

\section{Results:}

Sperm Motility: Fig. No.1, showed the effect of swim-up technique in sperm motility .1-Rapid progressive motility (RP):The mean percentage of RP before preparation was $31.74 \pm 5.68$, the increment in percentage of it after preparation was to $37.66 \% \pm 4.98$, and this increment was significant were the $(\mathrm{P}<0.05)$. 2-Non progressive motility (NP):The mean percentage of NP motility before preparation was $30.64 \pm 6.23$, the decrement in percentage of it after preparation was to $21.33 \pm$ 6.94 , and this decrement was significant were the $(\mathrm{P}$ $<0.05)$. 3- Immotility (IM)The mean percentage of IM before preparation was $37.67 \pm 5.97$, there was an increment in percentage of (IM) motility of sperm after preparation to $41.00 \pm 7.62$, and this increment was significant were the $(\mathrm{P}<0.05)$. 


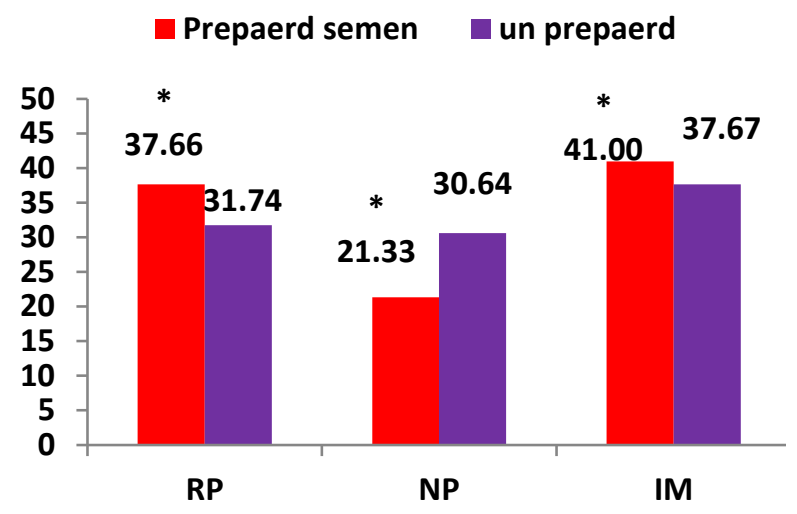

*Significant $(\mathbf{P}<\mathbf{0 . 0 5})$

Fig. No.1 showed the effect of swim -up Technique in sperm motility

DNA integrity by AOT : Fig. No.2, showed the effect of swim-up technique in DNA integrity by AOT, before preparation the DNA fragmentation percentage was $24.36 \% \pm 6.73$, the decrement in the DNA percentage after preparation was to $18.22 \% \pm 4.56$, and this decrement was significant were the $(\mathrm{P}<0.05)$.

\section{DNA Fragmentation \%}

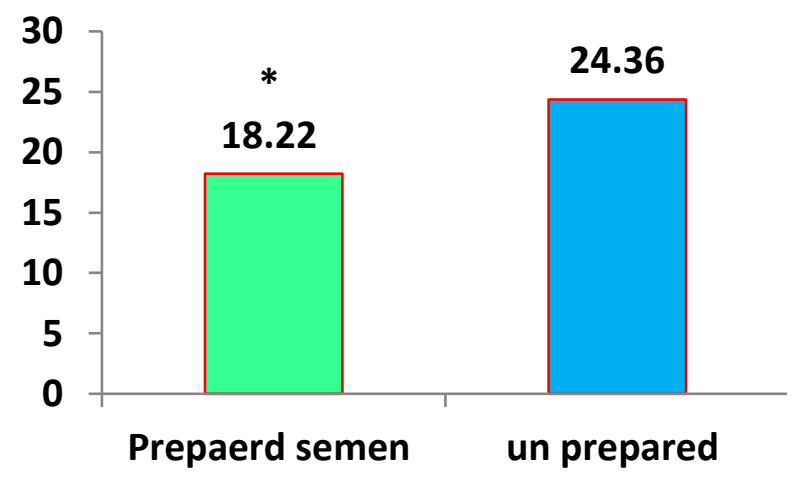

*Significant $(\mathbf{P}<\mathbf{0 . 0 5})$

Fig. No. 2.The Effect of swim-up techniques on DNA integrity by AOT.

index either by comet assay or by AOT and increase the sperm motility than that of raw semen, these results are similar to those in the literature, which shows that, DNA integrity of prepared spermatozoa, significantly greater than that of semen (15). Hashimoto, S. shown that swim-up technique improves sperm quality where eliminates morphologically abnormal spermatozoa and decreases DNA fragmentation index (DFI) so it is effective for improvement of embryo development (16). As well as other authors Thijssen A, (17), Malvezzi1, H. (18), Sakkas D. (19), Ricci G, (20), Gholamian M. (21) indicated in their articles that
DNA integrity by Comet assay: Fig. No. (3) showed the results of Comet assay (no damage (ND), low damage (LD), medium damage (MD), high damage (HD)) before and after swim-up. ND: Studying these results revealed that ND \% of sperm before preparation $(62.27 \pm 8.05 \%)$ and it is increased to $68.27 \pm 7.8 \%$ of prepared sperm. LD: Studying the results of LD \% of prepared sperm was $(19.46 \pm 4.33 \%)$, which is higher than that of before preparation $(15.11 \pm 3.71 \%)$. HD: Studying the results of HD \% of prepared sperm was (4.11 $1.49 \%)$ which less than that of before preparation $(15.03 \pm 4.02 \%)$ and the differences in ND, LD, HD types of DNA fragmentation was significant were the $(P<0.05)$, while MD: Studying the results MD $\%$ of prepared sperm was $(8.15 . \pm 3.26 \%)$ which is higher than that of before preparation (7.37 \pm $3.29 \%$ ) but the differences is not significant were the $(P>0.05)$.

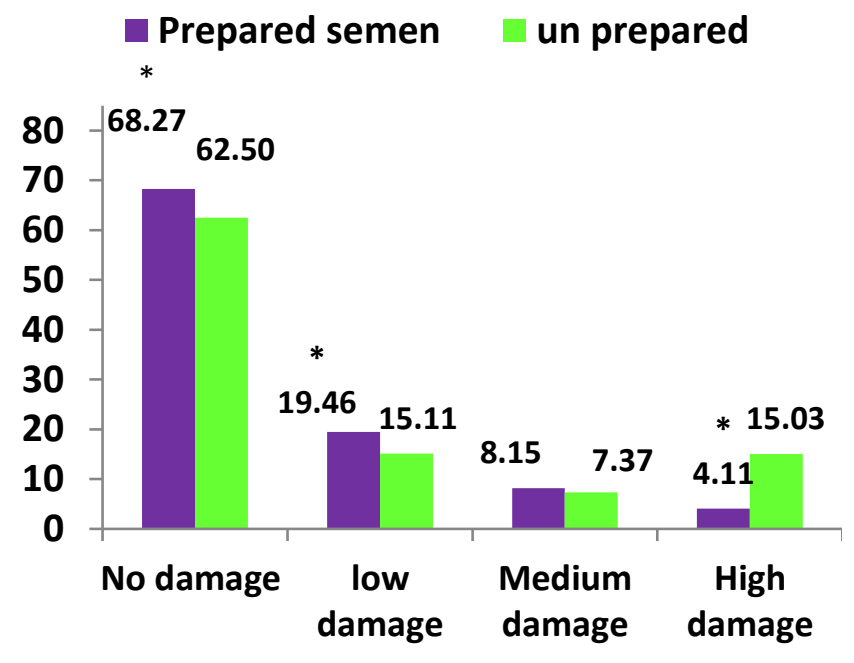

*Significant $(P<0.05)$

Fig. No. 3.The Effect of swim-up techniques on sperm motility and DNA integrity by Comet assay

Discussion :The present study indicates that swimup technique decreases the DNA fragmentation

preparation techniques provided a significantlybetter sperm population compared with the native sample. These results could be explained, the semen is likely to contain a number of dead or dying spermatozoa with abnormal morphology in addition to leukocytes which contribute to the higher percentage of DNA damage detected in semen compared to prepared spermatozoa. Therefore, it appears that in addition to isolating cells with the best motility and morphology, sperm preparation also eliminates dead and dying cells and isolates the spermatozoa with best DNA integrity. In other hands our findings are in contrast to results from other studies, where DNA 
integrity of prepared spermatozoa was significantly impaired in comparison with spermatozoa in semen , $(22,23,24,25,26)$, and could be explained by the results, that demonstrated a significant increase in the levels of ROS generated by samples prepared by swim-up from a washed pellet compared with spermatozoa isolated directly from seminal plasma. This oxidative stress was associated with a highly significant increase in the level of DNA damage sustained by the spermatozoa (27). While Younglai EV (28) and Anbari,F. (29) demonstrated no significant difference in DNA fragmentation rate in spermatozoa prepared by direct swim-up from the semen sample. The results of the both tests AOT and comet assay gave relatively similar predictive values for DNA fragmentation, although rapid fading of fluorescence, and heterogeneous staining of slides, and as some reports show that AOT gives higher DFI value makes AOT a test of questionable value in clinical practice However, the AOT, is simple, less expensive, quick procedure of DNA integrity evaluation test for diagnostic and prognostic purpose in basic andrology laboratories and can provide valuable information about overall sperm chromatin status. while the major limitation of comet assay, labor intensive, has observer subjectivity and requires experience to evaluate it (30) (31).

Conclusion: Swim up method of sperm preparation technique lead to increase sperm motility $\%$ and decrease DNA fragmentation.

\section{Authors contributions:}

Dr. Shatha Sadiq AL-Marayaty:, Collection of samples, do the tests, and analysis of data

Dr. Ghassan Thabet Saeed: Study conception and study design

Dr. Hazim Ismaeel AL-Ahmed: Statistical analysis and do the tests.

\section{References:}

1. Elder K, Dale B. (2011). Sperm and ART. Elder $K$, Dale $B$ (eds). $3^{\text {rd }}$ edition. In: In-Vitro Fertilization. 139-154. Cambridge UK. Cambridge University Press.

2. Twigg JP, Irvine DS and Aitken RJ, Oxidative damage to DNA in human spermatozoa does not preclude pronucleus formation at intracytoplasmic sperm injection. Hum. Reprod. 1998 13(7):18641871.

3. Tavalaee $M$, Razavi $S$ and Nasr-Esfahani $M H$, Influence of sperm chromatin anomalies on assisted reproductive technology outcome. Fertil. Steril. 2009; 91:1119-26.

4. Zini A, Boman JM, Belzile E, and Ciampi A, Sperm DNA damage is associated with an increased risk of pregnancy loss after IVF and ICSI: Systematic review and meta-analysis. Hum Reprod. 2008; 23:2663-2668.

5. Lopata A, Brown JB, and Leeton JF, In vitro fertilization of preovulatory oocytes and embryo transfer in infertile patients treated with clomiphene and human chorionic gonadotropin. Fertil. Steril. 1978; 30:27-35.

6. Zalata AA, Christophe AB, and Depuydt CE, The fatty acid composition of phospholipids of spermatozoa from infertile patients. Mol. Hum. Reprod. 1998; 4:111-118.

7. Aitken RJ, Clarkson JS, and Fishel S, Generation of reactive oxygen species, lipid peroxidation, and human sperm function. Biol Reprod. 1989; 40:183-197.

8. Henkel $R$, Hajimohammad $M$, and Stalf $T$, Influence of deoxyribonucleic acid damage on fertilization and pregnancy. Fertil. Steril. 2004; 81:965-72.

9. Chow CK, Vitamin E and oxidative stress. Free Radic. Biol. Med. 1991; 11:215-232.

10. Niki E, Action of ascorbic acid as scavenger of active and stable oxygen radicals. Am. J. Clin. Nutr. 1991; 54:1119-1124.

11. Kobayashi T, Miyazaki $T$, and Natori $M$, Protective role of superoxide dismutase in human sperm motility: Superoxide dismutase activity and lipid peroxide in human seminal plasma and spermatozoa. Hum. Reprod. 1991; 6: 987-991.

12. Mortimer D, (1989). Sperm Transport in the Human Female Reproductive Tract. Zsolt PN, Alex $C V$, and Ashok A(eds). In: In-Vitro Fertilization; Advanced Methods and Novel Devices. P: 30. Oxford UK. Oxford University Press.

13. Collins AR, Harrington V, Drew J, et al, Nutritional modulation of DNA repairs in a human intervention study. J. Carcinog. 2003; 24: 511 515 .

14. Tejada RI, Mitchell JC, Norman A, et al, A test for the practical evaluation of male fertility by Acridine orange (AO) fluoresces. Fertil. Steril. 1984; 42: 87-91.

15. Donnelly ET, O'Connell M, McClure $N$, et al, Differences in nuclear DNA fragmentation and mitochondrial integrity of semen and prepared human spermatozoa . Hum. Reprod. 2000; 15 (7): 1552-1561.

16. Hashimoto $S$, Goda $S$, Akamatsu $Y$, et al, Effects of sperm preparation on sperm DNA fragmentation and morphology. Reproductive Bio Medicine , 2008; $16: 26-28$.

17. Thijssen A, Klerkx E, Huyser $C$, et al, Influence of temperature and sperm preparation on the quality of spermatozoa Reproductive. Bio Medicine, 2014; 28 :436-442.

18. Malvezzil H, Sharmal $R$, Agarwal A, et al, Sperm quality after density gradient centrifugation with three commercially available media: A controlled trial. Reprod. Biol. Endocrinol. 2014; 12:121.

19. Sakkas D, Manicardi GC, Tomlinson M, et al, The use of two density gradient centrifugation techniques and the swim-up method to separate spermatozoa with chromatin and nuclear DNA anomalies. Hum. Reprod. 2000; 15: 1112-1116. 
20. Ricci G, Perticarari S, Boscolo R, et al, Semen preparation methods and sperm apoptosis: swim-up versus gradient-density centrifugation technique. Fertil. Steril. 2009 ; 91: 632-638.

21. Gholamian $M$, Jalali $M$, and Shamsa A, Effect of three sperm preparation methods on sperm DNA integrity and oocyte fertilization rate. Int. J. Fertil. Steril. 2013; 7: 56- 57.

22. Zini A, Mak V, Phang D, et al, Potential adverse effects of sperm processing on human sperm deoxyribonucleic acid integrity . Fertil. Steril. 1999; 72:496-499.

23. Matsuura R, Takeuchi $T$, and Yoshida, A, Preparation and incubation conditions affect the DNA integrity of ejaculated human spermatozoa. Asian J. Androl. 2010; 12: 753-759.

24. Chiamchanya C, Kaewnoonual N, Visutakul P, et al, Comparative study of the effects of three semen preparation media on semen analysis, DNA damage and protamine deficiency, and the correlation between DNA integrity and sperm parameters. Asian J. Androl. 2010; 12: 271-277.

25. Gosálvez J, Cortés-Gutiérrez EI, Nuñez R, et al, A dynamic assessment of sperm DNA fragmentation versus sperm viability in proven fertile human donors. Fertil. Steril. 2009; 92:1915-1919.

26. Dalzell LH, McVicar CM, McClure N, et al, Effects of short and long incubations on DNA fragmentation of testicular sperm. Fertil. Steril. 2004; 82:1443-1445.

27. Twigg J, Irvine DS, Houston, $P$, et al, Iatrogenic DNA damage induced in human spermatozoa during sperm preparation: Protective significance of seminal plasma. Mol. Hum. Reprod. 1998; 4:439-445

28. Younglai EV, Holt D, Brown P, et al, Sperm swim-up techniques and DNA fragmentation. Hum. Reprod. 2001; 16:1950-1953.

29. Anbari F, Halvaei I, Nabi A, et al, The quality of sperm preparation medium affects the motility, viability, and DNA integrity of human spermatozoa. J Hum. Reprod. Sci. 2016 ; 9(4): 254 258.

30. Shamsi M B, Imam SN, Dada R, Sperm DNA integrity assays: diagnostic and prognostic challenges and implications in management of infertility. J Assist Reprod Genet. 2011; 28(11): 1073-1085.

31. Duran EH, Gurgan T, Gunalp S, et al, A logistic regression model including DNA status and morphology of spermatozoa for prediction of fertilization in vitro. Hum Reprod. 1998;13:12351239. 